\title{
Do Bats Have the Necessary Prerequisites for Symbolic Communication?
}

\author{
Mirjam Knörnschild ${ }^{1,2,3 *}$ and Ahana A. Fernandez ${ }^{1}$ \\ 'Museum für Naturkunde, Leibniz-Institute for Evolution and Biodiversity Science, Berlin, Germany, ${ }^{2}$ Animal Behavior Lab, \\ Freie Universität, Berlin, Germany, ${ }^{3}$ Smithsonian Tropical Research Institute, Ancón, Panama
}

Training animals such as apes, gray parrots, or dolphins that communicate via arbitrary symbols with humans has revealed astonishing mental capacities that may have otherwise gone unnoticed. Albeit bats have not yet been trained to communicate via symbols with humans, we are convinced that some species, especially captive Pteropodid bats ("flying foxes"), show the potential to master this cognitive task. Here, we briefly review what is known about bats' cognitive skills that constitute relevant prerequisites for symbolic

OPEN ACCESS

Edited by:

Irene M. Pepperberg,

Harvard University, United States

Reviewed by: Kirsten Bohn,

Johns Hopkins University,

United States

Darren Burke,

The University of Newcastle, Australia Diana Reiss,

Hunter College (CUNY), United States

*Correspondence:

Mirjam Knörnschild mirjam.knoernschild@mfn.berlin; mirjam.knoernschild@gmail.com

Specialty section:

This article was submitted to Evolutionary Psychology, a section of the journal

Frontiers in Psychology

Received: 11 June 2020 Accepted: 12 October 2020 Published: 12 November 2020

Citation:

Knörnschild $M$ and

Fernandez AA (2020) Do Bats Have the Necessary Prerequisites for Symbolic Communication?

Front. Psychol. 11:571678. doi: 10.3389/fpsyg.2020.571678 communication with humans. We focus on social learning in general, trainability by humans, associative learning from humans, imitation, vocal production learning and usage learning, and social knowledge. Moreover, we highlight potential training paradigms that could be used to elicit simple "symbolic" bat-human communication, i.e., training bats to select arbitrary symbols on a touchscreen to elicit a desired behavior of the human caregiver. Touchscreen-proficient bats could participate in cognition research, e.g., to study their numerical competence or categorical perception, to further elucidate how nonhuman animals learn and perceive the world.

Keywords: symbols, indexical communication, social learning, cognitive skills, touchscreen, training paradigm, bats, associative learning

\section{INTRODUCTION}

Language is crucial to transmit information, share and accumulate knowledge across generations, and promote humans' cumulative culture (Tomasello, 2000; Herrmann et al., 2007; Fitch et al., 2010). Therefore, language drives and is driven by social cognition (Tomasello, 1992; Fitch et al., 2010). Besides a large set of physical cognitive skills, language particularly requires sociocognitive skills. Physical cognitive skills include memory, categorical perception and discrimination, perceptual processing, and recognition; and some researchers would also include general learning abilities such as fast mapping or associative learning as additional prerequisites (Gopnik et al., 1999; Vihman, 2014). Sociocognitive skills include, for example, social learning and theory of mind (Tomasello, 2003; Cheney and Seyfarth, 2007; Herrmann et al., 2007; Fitch et al., 2010). A remarkable form of social learning is our ability for imitation which plays a fundamental role in speech (or sign) acquisition (Oller, 1980; Petitto and Marentette, 1991; Vihman, 2014; Fitch, 2018). Infants acquire speech through imitation of the fundamental speech subunits, i.e., syllables, based on auditory input (Oller, 1980; Vihman et al., 1986). Whereas the ability of vocal production learning, i.e., the modification of one's own oral output 
based on social input, represents the mechanistic part of speech production, social knowledge is required to develop the semantic capacities of language (Tomasello, 1992, 2000; Fitch et al., 2010). The cognitive skills of joint attention, gaze responsiveness, and pointing pave the way for the developing the theory of mind in young infants (Carpenter and Tomasello, 1995; Gopnik et al., 1999; Tomasello, 2003). Joint attention, for example, is important for understanding others and enhances word learning (MacNamara, 1972; Gopnik et al., 1999; Tomasello, 2003). The development of these sociocognitive skills and, ultimately, language acquisition are shaped and promoted through social interaction (Tomasello, 1992; Kuhl, 2007; Goldstein and Schwade, 2010). Social feedback is also important for non-human vocal production learners (Goldstein and Schwade, 2010; Beecher, 2017; García, 2019), in particular, when learning non-species-specific vocalizations as the interaction in itself is already a form of communication (Pepperberg, 1992, 1994, 2002), or when learning to communicate via arbitrary symbols (Reiss and McCowan, 1993).

Language can be understood as a system of symbols whose elements (for example, words) can be arranged according to rules (through grammar) to create new meaningful units (such as sentences). Thus, the power of human symbolic communication is based upon the fact that the meaning of words can gain additional meaning through their relationship to other words, i.e., a sign-sign relationship (Sinha, 2004; Nieder, 2009). In contrast, non-human animal communication systems have indexical referential associations, i.e., they are based on a direct physical or temporal relation between sign-object or sign-event (Sinha, 2004; Nieder, 2009). The evolutionary transition from indexical communication in animals to symbolic communication in humans is considered to be associated with the emergence of language and symbolic thought (Deacon, 1998; Sinha, 2004; Nieder, 2009; Grouchy et al., 2016).

Even though only humans are thought to possess naturally occurring symbolic communication systems (i.e., natural languages, numerical systems), several other species such as apes, gray parrots, and dolphins can be trained to use symbols to express their needs/preferences when communicating with conspecifics (Fouts et al., 1984; Cianelli and Fouts, 1998; Pepperberg, 2009) or with humans (Gardner and Gardner, 1969; Herman et al., 1984; Schusterman and Krieger, 1984; Gisiner and Schusterman, 1992; Reiss and McCowan, 1993; Sevcik and Savage-Rumbaugh, 1994; Pepperberg, 2009). Symbolic communication between humans and animals can involve acoustic signals and speech (Herman et al., 1984; Pepperberg, 2009), gestures (Herman et al., 1984; Schusterman and Krieger, 1984, 1986), and technical interfaces such as TV monitors (Herman et al., 1990), interactive keyboards (Savage-Rumbaugh and Rumbaugh, 1978; Savage-Rumbaugh et al., 1980; Reiss and McCowan, 1993), or touchscreens (Nilsson et al., 2004; Amundin et al., 2008).

Training animals to communicate via arbitrary symbols has revealed astonishing mental capacities (Pepperberg, 1987, 2006; Boysen and Berntson, 1989; Reiss and McCowan, 1993; SavageRumbaugh and Fields, 2000; Kilian et al., 2003) which could have been overlooked if only the animals' naturally occurring communication signals had been decoded. When animals communicate with humans via learned arbitrary symbols, signobject and sign-event relations are much more common than sign-sign relations (Sevcik and Savage-Rumbaugh, 1994; Pepperberg, 2009). Nevertheless, this simple "symbolic" communication is highly useful for understanding which cognitive prerequisites were necessary for the evolution of true symbolic communication, i.e., language in humans. Moreover, it allows for an in-depth investigation of speciesspecific mental capacities. Researchers documented, for example, cognitive skills such as numerical competence (Boysen and Berntson, 1989; Pepperberg, 2006), concept formation (Pepperberg, 1987), associative learning capabilities, and selforganized learning events (Reiss and McCowan, 1993).

Here, we want to give our perspective on the potential capability of bats to communicate with humans by using arbitrary symbols. Albeit bats have not yet been trained to communicate via symbols with humans, we are convinced for reasons that we outline below, that they show the potential to master this cognitive task. Bats are a very gregarious taxon comprising $>1,400$ extant species and exhibit a large spectrum of social systems with differing degrees of complexity (Wilkinson et al., 2019). Because taxonomic breadth is crucial for studying cognitive adaptations and achievements (Dukas, 2004), bats are an important taxon for comparative cognition research. Many bat species are long-lived (up to 30 years in the wild; Barclay and Harder, 2003) and most species either live in perennial stable groups (Wilkinson and Boughman, 1998) or have a social organization characterized by fission-fusion dynamics (Kerth, 2008). Both forms of temporal consistency in social interactions between group members pose different requirements on the cognitive abilities of the animals because they differ considerably in terms of relevant group size, frequency of repeated encounters, and consistency of social relationships.

Acoustic communication is one of the main channels for information transfer used by bats (Chaverri et al., 2018). In addition to echolocation (i.e., for navigation and foraging), different bat species possess diverse vocal repertoires and specific vocalization types which encode various information types such as emotional state (Bastian and Schmidt, 2008; Walter and Schnitzler, 2019) and identity information such as social group affiliation (Wilkinson and Boughman, 1998; Knörnschild et al., 2012), age (Jones et al., 1991; Fernandez and Knörnschild, 2017), and individual signatures (Carter et al., 2008; Chaverri et al., 2010). Vision and olfaction, the other two main sensory modalities in bats, are less well understood. Both phylogeny and species-specific dietary preferences influence bats' visual capabilities (Figure 1): whereas most Old Word fruit bats (Pteropodidae) rely almost exclusively on vision for orientation (Möhres and Kulzer, 1956), only some members of the genus Rousettus can use rudimentary echolocation based on tongue clicks (Grinnell and Hagiwara, 1972). Acoustics are of crucial importance to insectivorous bats which capture their prey via echolocation (Neuweiler, 1989). In contrast to insectivorous bats, nectarivorous and frugivorous bats have comparably larger eyes and a better 


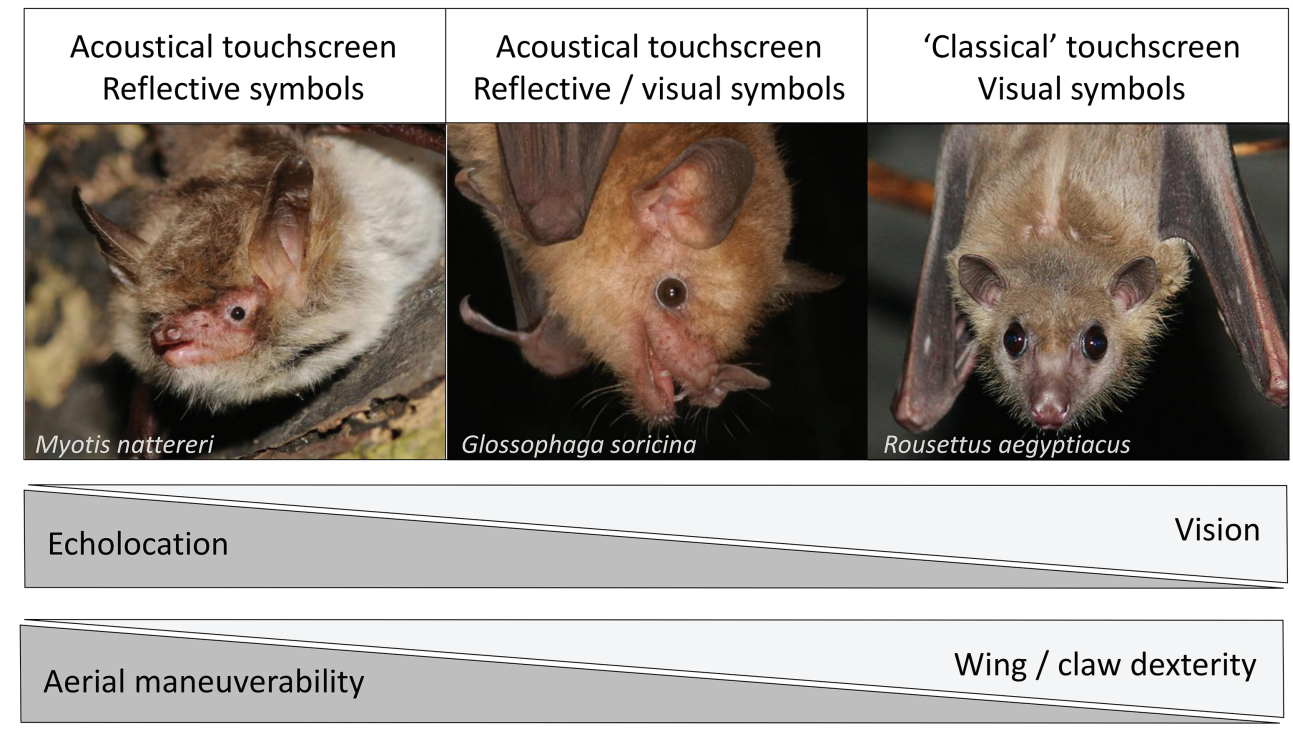

FIGURE 1 | Knowledge about species-specific strength and weaknesses in perception, maneuverability, and dexterity must inform the training paradigms for bathuman communication, e.g., with a touchscreen. Whereas most bats rely on echolocation to perceive the world, many species also use vision to a certain degree. For the Pteropodid bats ("flying foxes"), vision is the most important sense and only some members of the genus Rousettus can use rudimentary echolocation based on tongue clicks. Whereas Pteropodid bats reach comparatively high levels of dexterity with their wings and claws and often use them to manipulate objects, many non-Pteropodid bats do not. In turn, non-Pteropodid bats generally show greater aerial maneuverability than Pteropodid bats. Thus, visually oriented bats with high dexterity should be trained to use a "classical" touchscreen with visual symbols which they can approach by crawling/climbing whereas echoacoustically oriented bats with high aerial maneuverability should be trained to use a touchscreen with reflective symbols which they can activate with their sonar beam while hovering in front of it. If necessary, intermediate forms of these two extremes should be used to best accommodate a species' capabilities. The three depicted bat species represent the range of diverse species covered in the text: Myotis nattereri, an insectivorous gleaner (photo credit: Ján Svetlik), Glossophaga soricina, a nectarivorous flower-visiting bat (photo credit: Marco Tschapka), and Rousettus aegyptiacus, a frugivorous pteropodid (photo credit: Lithuanian Zoological Gardens).

vision (Zhao et al., 2009), even though they predominantly rely on echolocation as well, especially at short range-distances (Winter et al., 2005; Holland, 2007). Olfaction plays an important additional role for foraging Pteropodids and frugivorous or nectarivorous Neotropical bats (Korine and Kalko, 2005; Raghuram et al., 2009; Gonzalez-Terrazas et al., 2016). Olfactory signals are also important mediators for social communication (Safi and Kerth, 2003; Voigt et al., 2008). However, bat olfaction will not be discussed further as this sensory modality is not well suited for training paradigms discussed later.

In the following, we briefly review what cognitive skills that constitute relevant prerequisites for symbolic communication are already known to be present in bats. Furthermore, we highlight potential training paradigms which could be used to elicit simple "symbolic" bat-human communication, i.e., bats using learned arbitrary symbols to elicit a desired behavior of the human caregiver. We hope to highlight practical approaches for future studies on symbolic communication in bats.

\section{SOCIAL LEARNING}

Social learning occurs when animals learn from others that they observe or with whom they interact, for example, about foraging strategies or predator avoidance (Hoppitt and Laland, 2013).
In bats, social learning is widespread and includes learning about roost- or food-related information as well as vocal production learning (reviewed in Wilkinson and Boughman, 1999; Wright, 2016). Learning from conspecifics has received much more attention than learning from heterospecific bats (Page and Bernal, 2020); the latter has been investigated in only a few species so far (Clarin et al., 2014; Patriquin et al., 2018). Moreover, the majority of studies demonstrated horizontal social learning, i.e., adults learning from adults, whereas vertical social learning, i.e., pups learning from adults, is currently understudied and yields both positive (Ripperger et al., 2019) and negative results (Rose et al., 2019). Although bats learn faster from other bats than from humans (Gaudet and Fenton, 1984; Clarin et al., 2014), humans can nevertheless elicit associative learning in bats and train them to perform specific actions (reviewed in Siemers and Page, 2009).

\section{ASSOCIATIVE LEARNING}

Bats readily learn to associate a particular cue with a specific outcome, either by themselves via trial-and-error learning or from others via social learning. Associative learning has been mainly demonstrated in a foraging context (reviewed in Wilkinson and Boughman, 1999; Wright, 2016). Bats can be trained to associate various novel cues with a food reward, 
e.g., light cues (Clarin et al., 2014), acoustic cues (Jones et al., 2013), echoacoustic, i.e., reflective cues (Simon et al., 2014), olfactory cues (Page et al., 2012), and visual cues (Manske and Schmidt, 1979). Gleaning bats, i.e., species that capture prey from substrates, seem to be especially well suited for food-related associative learning tasks (Siemers, 2001; Page and Ryan, 2006; Hulgard and Ratcliffe, 2014; Patriquin et al., 2018). Nectarivorous bats also exhibit strong associative learning in a foraging context and can be trained to discriminate fine-scale differences between sensory cues (von Helversen, 2004; Simon et al., 2006; Ross and Holderied, 2013) but they generally rely more on spatial cues than sensory cues (Thiele and Winter, 2005; Stich and Winter, 2006; Carter et al., 2010). Insectivorous bats can be trained to recognize 3-D objects as acoustic landmarks and associate them with safe passage through a net opening (Yu et al., 2019). In many species, learned associations are flexible and bats can be trained to reverse their initial associations (Page and Ryan, 2005; Clarin et al., 2013; Ross and Holderied, 2013). There is very little data on how long learned associations are remembered but current evidence suggests that bats have good short- and long-term memory (Ruczyński and Siemers, 2011; Page et al., 2012; Clarin et al., 2014; but see: Hernández-Montero et al., 2020). The above-mentioned examples used positive reinforcement but associative learning can also be negatively reinforced. Bats readily acquire taste aversions, e.g., by associating a novel acoustic cue with a noxious food reward (Bates and Fenton, 1990) or a novel flavor cue with an episode of toxicosis (Ratcliffe et al., 2003).

\section{TRAINABILITY BY HUMANS}

Various techniques can be applied to coax bats to participate in associative learning tasks (reviewed in Siemers and Page, 2009). Two important techniques for training bats are fading and shaping (Terrace, 1963; Shettleworth, 1998; Domjan, 2003). When fading, bats are gradually introduced to a new stimulus by altering the stimulus in small steps (Jones et al., 2013; Hemingway et al., 2020). Fading is especially important when studying reversal learning as it also allows the removal of a bat's response to a known stimulus (Page and Ryan, 2005, 2006). When shaping, the desired response of a bat is increasingly reinforced while non-desired responses are not reinforced (Barber et al., 2003). Shaping is also the technique of choice when training bats to perform certain behaviors on command. Captive Pteropodid bats ("flying foxes") can be readily trained for husbandry and vet checks; for instance, they can learn to follow a target, to unfold their wings in response to a hand signal, and to touch an item on demand (pers. communication Brian Pope, Lubee Bat Conservancy, USA). We are not aware that non-Pteropodid bats are being trained for husbandry and vet checks. However, temporarily captive non-Pteropodid bats can be trained to approach humans to retrieve a food reward, to wait on a perch until the onset of a stimulus, and to fly to a specific position when perceiving a stimulus (Tuttle, 2019).

\section{IMITATION}

Several bat species are capable of imitating conspecifics' actions. Naïve individuals have been shown to learn about novel foraging situations by paying close attention to knowledgeable conspecifics (Eptesicus fuscus: Wright et al., 2011; Antrozous pallidus: Bunkley and Barber, 2014). Imitation has also been shown in a communicative context, namely, when pups learn to sing by imitating the song of adult tutors (Saccopteryx bilineata: Knörnschild et al., 2010).

\section{VOCAL PRODUCTION LEARNING AND USAGE LEARNING}

Imitating new signals is one form of vocal production learning (VPL), modifying existing signals based on social influences is another (Janik and Slater, 1997, 2000). VPL via social modification has been shown for social calls (Rousettus aegyptiacus: Prat et al., 2015, 2017; Genzel et al., 2019; Saccopteryx bilineata: Knörnschild et al., 2012; Phyllostomus discolor: Esser and Schmidt, 1989; Esser, 1998; Lattenkamp et al., 2020; P. hastatus: Boughman, 1998) and echolocation calls (Rhinolophus ferrumequinum: Jones and Ransome, 1993; Hipposideros terasensis: Hiryu et al., 2006). In addition to VPL, vocal usage learning has been demonstrated by training temporarily isolated bats to vocalize in order to trigger a food reward ( $P$. discolor: Lattenkamp et al., 2018). It is plausible that more bat species may have some degree of volitional control over their vocalizations but data are currently lacking.

\section{SOCIAL KNOWLEDGE}

Social knowledge describes the cognitive assessment of cues that communicate socially relevant information (Cheney et al., 1986). Whereas social knowledge mainly constitutes learning about others, such as their status or intentions, sociocognitive skills also facilitate the interpretation of signals or cues from others outside a social context (e.g., using gaze following to identify the location of food that a conspecific has hidden; Tomasello et al., 1998). In bats, social knowledge is severely understudied and most circumstantial evidence concerns comparatively simple sociocognitive skills such as the maintenance of dominance hierarchies (Neuweiler, 1969) or territorial interactions (Voigt and Streich, 2003). Advanced sociocognitive skills such as gaze following, joint attention, point following, and theory of mind are found to varying degrees in highly intelligent social species, such as primates and corvids, and also in domesticated species such as dogs; they can include heterospecific interactions, for example with humans (reviewed in Fitch et al., 2010). Evidence for heterospecific social knowledge in bats is currently limited to one study which demonstrated that captive born individuals of different bat species (Pteropus pumilus, $P$. rodricensis, and $P$. conspicillatus) are responsive to human pointing gestures (Hall et al., 2011): experimentally naïve bats readily utilize 
human pointing to find the location of concealed food in an object-choice task. The observed spontaneous point-following behavior suggests advanced sociocognitive skills in these bats. Interestingly, only captive born individuals were sensitive to human gestures; captive individuals born in the wild (P. pumilus and $P$. vampyrus) were not (Hall et al., 2011). It is possible that direct contact with humans early in ontogeny is necessary for bats to exhibit heterospecific point-following behavior.

\section{DISCUSSION}

There is conclusive evidence, albeit sometimes anecdotal, that different bat species possess several key prerequisites necessary for symbolic communication, most importantly associative learning and a general readiness to interact with and learn from caregivers in captivity. However, it is important to note that the ability for associative learning alone is not a guarantee that bats can transfer simple associations to more complex symbolic representations. What is missing so far is an experimental approach that actively combines these abilities to test if rudimentary symbolic bat-human communication can be achieved.

If attempted, we suggest making the task as easy as possible in both implementation and perception to facilitate the initial communication process. Training bats to communicate their choice between different preferred food items via arbitrary symbols would be a promising starting point to implement bat-human communication. Touchscreens are very promising tools for animal-human communication because they can be activated via fingers, snouts, tongues, beaks, and sonar beams, thus, making them accessible to a wide range of taxa (reviewed in Egelkamp and Ross, 2019). Bats would need (1) to learn to operate a touchscreen, (2) learn the association of a certain symbol with a specific food item, and (3) to use the symbol when communicating with a human via a touchscreen (Figure 2).

Accommodating species-specific differences in perception is crucial for the success of this endeavor (Figure 1). Visually oriented bats such as Pteropodids could be trained to use a touchscreen with visual symbols representing different preferred food items, as has been successfully done with primates (SavageRumbaugh, 1993). Echoacoustically oriented bats could be trained to use an acoustically activated touchscreen instead. This method, termed Echo Location Visualization and Interface System (ELVIS), has been developed for dolphins (Nilsson et al., 2004; Amundin et al., 2008) and allows them to use their sonar beam to "touch" and, thus, choose items on a screen, e.g., to communicate food preferences (Starkhammar et al., 2007). For bats, an acoustically activated touchscreen would ideally not depict visual symbols but reflective symbols (e.g., reliefs) to facilitate perception.

Even though bats are capable of vocal production and usage learning, we would advise against the use of acoustic symbols to facilitate bat-human communication. In contrast to certain songbirds, parrots, and dolphins, the imitation of heterospecific

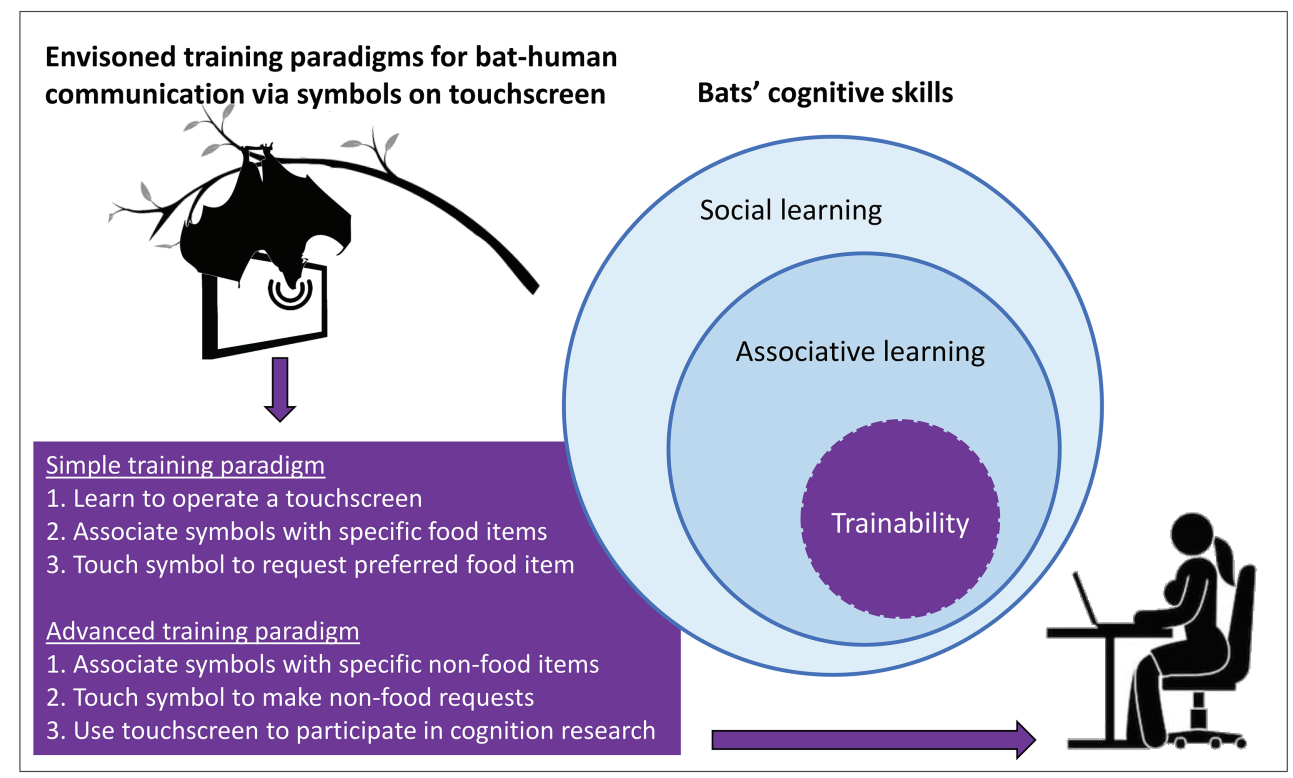

FIGURE 2 | Envisioned training paradigms for bat-human communication via symbols on a touchscreen. A set of different cognitive skills should enable bats to use a touchscreen, most importantly their capability of associative learning in a social context. We suggest focusing on visual or echoacoustic, i.e., reflective symbols on a touchscreen. A simple training paradigm requires bats to learn to operate a touchscreen by touching visual symbols with their snout (or reflective symbols with their sonar beam), to associate different symbols with specific food items, and to use these symbols to communicate which food item they prefer to receive (signobject relation). An advanced training paradigm requires bats to associate different symbols with specific non-food items, e.g., caresses, access to toys, etc., and to use these symbols to communicate their preference (sign-event or sign-object relation). Touchscreen-proficient bats can participate in cognition research, e.g., to study their numerical competence or categorical perception. 
sounds has never been demonstrated in bats. Because heterospecific vocal imitation is crucial for using novel sounds as symbols, we suggest focusing on visual or echoacoustic, i.e., reflective symbols for bat-human communication instead.

To conclude, bats are a promising taxon for future studies on symbolic communication with humans. Their willingness to interact with caregivers, associative learning abilities, and advanced (socio-)cognitive skills are important prerequisites to communicate successfully with humans. If bat-human communication about food requests could indeed be established, it would be an ideal stepping stone for a more advanced comparative cognition research, further elucidating how nonhuman animals think and learn.

\section{AUTHOR CONTRIBUTIONS}

$\mathrm{MK}$ and $\mathrm{AF}$ reviewed the literature and wrote the manuscript. Both the authors contributed to the article and approved the submitted version.

\section{REFERENCES}

Amundin, M., Starkhammar, J., Evander, M., Almqvist, M., Lindstrom, K., and Persson, H. W. (2008). An echolocation visualization and interface system for dolphin research. J. Acoust. Soc. Am. 123, 1188-1194. doi: 10.1121/1.2828213

Barber, J. R., Razak, K. A., and Fuzessery, Z. M. (2003). Can two streams of auditory information be processed simultaneously? Evidence from the gleaning bat Antrozous pallidus. J. Comp. Physiol. A 189, 843-855. doi: 10.1007/ s00359-003-0463-6

Barclay, R. M. R., and Harder, L. D. (2003). "Life histories of bats: life in the slow lane" in Bat ecology. eds. T. H. Kunz and B. Fenton (London: The University of Chicago Press, Ltd), 209-256.

Bastian, A., and Schmidt, S. (2008). Affect cues in vocalizations of the bat, Megaderma lyra, during agonistic interactions. J. Acoust. Soc. Am. 124, 598-608. doi: 10.1121/1.2924123

Bates, D. L., and Fenton, M. B. (1990). Aposematism or startle? Predators learn their responses to the defenses of prey. Can. J. Zool. 68, 49-52. doi: 10.1139/z90-009

Beecher, M. D. (2017). Birdsong learning as a social process. Anim. Behav. 124, 233-246. doi: 10.1016/j.anbehav.2016.09.001

Boughman, J. W. (1998). Vocal learning by greater spear-nosed bats. Proc. R. Soc. Lond. B Biol. Sci. 265, 227-233. doi: 10.1098/rspb.1998.0286

Boysen, S. T., and Berntson, G. G. (1989). Numerical competence in a chimpanzee (Pan troglodytes). J. Comp. Psychol. 103, 23-31. doi: 10.1037/0735-7036. 103.1.23

Bunkley, J. P., and Barber, J. R. (2014). An observation of apparent teaching behavior in the pallid bat, Antrozous pallidus. West. N. Am. Nat. 74, 249-252. doi: $10.3398 / 064.074 .0213$

Carpenter, M., and Tomasello, M. (1995). Joint attention and imitative learning in children, chimpanzees, and enculturated chimpanzees. Soc. Dev. 4, 217-237. doi: 10.1111/j.1467-9507.1995.tb00063.x

Carter, G. G., Ratcliffe, J. M., and Galef, B. G. (2010). Flower bats (Glossophaga soricina) and fruit bats (Carollia perspicillata) rely on spatial cues over shapes and scents when relocating food. PLoS One 5:e10808. doi: 10.1371/ journal.pone.0010808

Carter, G. G., Skowronski, M. D., Faure, P. A., and Fenton, B. (2008). Antiphonal calling allows individual discrimination in white-winged vampire bats. Anim. Behav. 76, 1343-1355. doi: 10.1016/j.anbehav.2008.04.023

Chaverri, G., Ancillotto, L., and Russo, D. (2018). Social communication in bats. Biol. Rev. 93, 1938-1954. doi: 10.1111/brv.12427

Chaverri, G., Gillam, E. H., and Vonhof, M. J. (2010). Social calls used by a leaf-roosting bat to signal location. Biol. Lett. 6, 441-444. doi: 10.1098/rsbl.2009.0964

\section{FUNDING}

This study was financed by a Heisenberg Fellowship (DFG KN935 5-1) awarded to MK and an Elsa-Neuman Fellowship awarded to AF. The research leading to these results has received funding from the European Research Council under the European Union's Horizon 2020 Programme (2014-2020)/ ERC GA 804352.

\section{ACKNOWLEDGMENTS}

We are indebted to Irene Pepperberg, Diana Reiss, and two reviewers for their constructive feedback. We also thank Martina Nagy and Simon Ripperger for their comments on the manuscript and Merlin Tuttle and Brian Pope for sharing their knowledge on training paradigms. Moreover, we are grateful to Ján Svetlík, Marco Tschapka, and the Lithuanian Zoological Gardens for contributing bat photos. We acknowledge support by the Open Access Publication Initiative of Freie Universität Berlin.

Cheney, D. L., and Seyfarth, R. M. (2007). Baboon metaphysics: The evolution of a social mind Chicago. IL: University of Chicago Press.

Cheney, D., Seyfarth, R., and Smuts, B. (1986). Social relationships and social cognition in nonhuman primates. Science 234, 1361-1366. doi: 10.1126/ science. 3538419

Cianelli, S. N., and Fouts, R. S. (1998). Chimpanzee to chimpanzee American sign language. J. Hum. Evol. 13, 147-159. doi: 10.1007/BF02436502

Clarin, T. M. A., Borissov, I., Page, R. A., Ratcliffe, J. M., and Siemers, B. M. (2014). Social learning within and across species: information transfer in mouse-eared bats. Can. J. Zool. 92, 129-139. doi: 10.1139/cjz-2013-0211

Clarin, T. M. A., Ruczyński, I., Page, R. A., and Siemers, B. M. (2013). Foraging ecology predicts learning performance in insectivorous bats. PLoS One 8:e64823. doi: 10.1371/journal.pone.0064823

Deacon, T. W. (1998). The symbolic species: The co-evolution of language and the brain. New York: W.W. Norton and Company Inc.

Domjan, M. (2003). The principles of learning and memory. 5th Edn. Belmont, California: Wadsworth.

Dukas, R. (2004). Evolutionary biology of animal cognition. Annu. Rev. Ecol. Evol. Syst. 35, 347-374. doi: 10.1146/annurev.ecolsys.35.112202.130152

Egelkamp, C. L., and Ross, S. R. (2019). A review of zoo-based cognitive research using touchscreen interfaces. Zoo Biol. 38, 220-235. doi: 10.1002/zoo.21458

Esser, K. H. (1998). "Psychoacoustic studies in neotropical bats" in Clinical psychoacoustics. eds. S. Nielzén and O. Olsson (Sweden: Lund University Press), 45-59.

Esser, K. H., and Schmidt, U. (1989). Mother-infant communication in the lesser spear-nosed bat Phyllostomus discolor (Chiroptera, Phyllostomidae)evidence for acoustic learning. Ethology 82, 156-168. doi: 10.1111/j.14390310.1989.tb00496.x

Fernandez, A. A., and Knörnschild, M. (2017). Isolation calls of the bat Saccopteryx bilineata encode multiple messages. Anim. Behav. Cogn. 4, 169-186. doi: 10.12966/abc.04.05.2017

Fitch, W. T. (2018). The biology and evolution of speech: a comparative analysis. Annu. Rev. Linguist. 4, 255-279. doi: 10.1146/annurev-linguistics-011817-045748

Fitch, W. T., Huber, L., and Bugnyar, T. (2010). Social cognition and the evolution of language: constructing cognitive phylogenies. Neuron 65, 795-814. doi: 10.1016/j.neuron.2010.03.011

Fouts, R. S., Fours, D. H., and Schoenfeld, D. (1984). Sign language conversational interaction between chimpanzees. Sign Lang. Stud. 42, 1-12.

García, N. C. (2019). What have we recently learned about song learning and social interactions? Behav. Ecol. 30, 1193-1195. doi: 10.1093/beheco/arz098

Gardner, R. A., and Gardner, B. T. (1969). Teaching sign language to a chimpanzee. Science 165, 664-672. 
Gaudet, C. L., and Fenton, B. M. (1984). Observational learning in three species of insectivorous bats (Chiroptera). Anim. Behav. 32, 385-388. doi: 10.1016/ S0003-3472(84)80273-0

Genzel, D., Desai, J., Paras, E., and Yartsev, M. M. (2019). Long-term and persistent vocal plasticity in adult bats. Nat. Commun. 10, 1-12. doi: 10.1038/ s41467-019-11350-2

Gisiner, R., and Schusterman, R. J. (1992). Sequence, syntax, and semantics: responses of a language-trained sea lion (Zalophus californianus) to novel sign combinations. J. Comp. Psychol. 106, 78-91. doi: 10.1037/0735-7036.106.1.78

Goldstein, M. H., and Schwade, J. A. (2010). "From birds to words: perception of structure in social interactions guides vocal development and language learning" in The Oxford handbook of developmental and comparative neuroscience. eds. M. S. Blumberg, J. H. Freeman and S. R. Robinson (Oxford: Oxford University Press), 708-729.

Gonzalez-Terrazas, T. P., Martel, C., Milet-Pinheiro, P., Ayasse, M., Kalko, E. K., and Tschapka, M. (2016). Finding flowers in the dark: nectar-feeding bats integrate olfaction and echolocation while foraging for nectar. R. Soc. Open Sci. 3:160199. doi: 10.1098/rsos.160199

Gopnik, A., Meltzoff, A. N., and Kuhl, P. (1999). The scientist in the crib: What early learning tells us about the mind. New York: Harper Collins Publishers Inc.

Grinnell, A. D., and Hagiwara, S. (1972). Studies of auditory neurophysiology in non-echolocating bats, and adaptations for echolocation in one genus, Rousettus. Z. Vergl. Physiol. 76, 82-96. doi: 10.1007/BF00395501

Grouchy, P., D'Eleuterio, G. M., Christiansen, M. H., and Lipson, H. (2016). On the evolutionary origin of symbolic communication. Sci. Rep. 6, 1-9. doi: $10.1038 /$ srep34615

Hall, N. J., Udell, M. A., Dorey, N. R., Walsh, A. L., and Wynne, C. D. (2011). Megachiropteran bats (Pteropus) utilize human referential stimuli to locate hidden food. J. Comp. Psychol. 125, 341-346. doi: 10.1037/a0023680

Hemingway, C. T., Ryan, M. J., and Page, R. A. (2020). State-dependent learning influences foraging behaviour in an acoustic predator. Anim. Behav. 163, 33-38. doi: 10.1016/j.anbehav.2020.02.004

Herman, L. M., Morrel-Samuels, P., and Pack, A. A. (1990). Bottlenosed dolphin and human recognition of veridical and degraded video displays of an artificial gestural language. J. Exp. Psychol. Gen. 119, 215-230. doi: 10.1037/0096-3445.119.2.215

Herman, L. M., Richards, D. G., and Wolz, J. P. (1984). Comprehension of sentences by bottlenosed dolphins. Cognition 16, 129-219. doi: 10.1016/0010-0277(84)90003-9

Hernández-Montero, J. R., Schöner, C. R., and Kerth, G. (2020). No evidence for memory retention of a learned association between a cue and roost quality after hibernation in free-ranging bats. Ethology 126, 761-771. doi: 10.1111/eth.13029

Herrmann, E., Call, J., Hernández-Lloreda, M. V., Hare, B., and Tomasello, M. (2007). Humans have evolved specialized skills of social cognition: the cultural intelligence hypothesis. Science 317, 1360-1366. doi: 10.1126/ science. 1146282

Hiryu, S., Katsura, K., Nagato, T., Yamazaki, H., Lin, L. -K., Watanabe, Y., et al. (2006). Intra-individual variation in the vocalized frequency of the Taiwanese leaf-nosed bat, Hipposideros terasensis, influenced by conspecific colony members. J. Comp. Physiol. A 192, 807-815. doi: 10.1007/s00359-006-0118-5

Holland, R. A. (2007). Orientation and navigation in bats: known unknowns or unknown unknowns? Behav. Ecol. Sociobiol. 61, 653-660. doi: 10.1007/ s00265-006-0297-7

Hoppitt, W., and Laland, K. N. (2013). Social learning: An introduction to mechanisms, methods, and models. Princeton: Princeton University Press.

Hulgard, K., and Ratcliffe, J. M. (2014). Niche-specific cognitive strategies: object memory interferes with spatial memory in the predatory bat Myotis nattereri. J. Exp. Biol. 217, 3293-3300. doi: 10.1242/jeb.103549

Janik, V. M., and Slater, P. J. B. (1997). "Vocal learning in mammals" in Advances in the study of behavior. eds. P. J. B. Slater, J. S. Rosenblatt, C. T. Snowdon and M. Milinski (USA: Academic Press), 59-100.

Janik, V. M., and Slater, P. J. (2000). The different roles of social learning in vocal communication. Anim. Behav. 60, 1-11. doi: 10.1006/anbe.2000.1410

Jones, G., Hughes, P. M., and Rayner, J. M. V. (1991). The development of vocalizations in Pipistrellus pipistrellus (Chiroptera: Vespertilionidae) during post-natal growth and the maintenance of individual vocal signatures. J. Zool. 225, 71-84. doi: 10.1111/j.1469-7998.1991.tb03802.x
Jones, G., and Ransome, R. D. (1993). Echolocation calls of bats are influenced by maternal effects and change over a lifetime. Proc. R. Soc. Lond. B Biol. Sci. 252, 125-128. doi: 10.1098/rspb.1993.0055

Jones, P. L., Ryan, M. J., Flores, V., and Page, R. A. (2013). When to approach novel prey cues? Social learning strategies in frog-eating bats. Proc. R. Soc. Lond. B Biol. Sci. 280:20132330. doi: 10.1098/rspb.2013.2330

Kerth, G. (2008). Causes and consequences of sociality in bats. Bioscience 58, 737-746. doi: 10.1641/B580810

Kilian, A., Yaman, S., von Fersen, L., and Güntürkün, O. (2003). A bottlenose dolphin discriminates visual stimuli differing in numerosity. Anim. Learn. Behav. 31, 133-142. doi: 10.3758/BF03195976

Knörnschild, M., Nagy, M., Metz, M., Mayer, F., and von Helversen, O. (2010). Complex vocal imitation during ontogeny in a bat. Biol. Lett. 6, 156-159. doi: $10.1098 / \mathrm{rsbl} .2009 .0685$

Knörnschild, M., Nagy, M., Metz, M., Mayer, F, and von Helversen, O. (2012). Learned vocal group signatures in the polygynous bat Saccopteryx bilineata. Anim. Behav. 84, 761-769. doi: 10.1016/j.anbehav.2012.06.029

Korine, C., and Kalko, E. K. (2005). Fruit detection and discrimination by small fruit-eating bats (Phyllostomidae): echolocation call design and olfaction. Behav. Ecol. Sociobiol. 59, 12-23. doi: 10.1007/s00265-005-0003-1

Kuhl, P. K. (2007). Is speech learning "gated" by the social brain? Dev. Sci. 10, 110-120. doi: 10.1111/j.1467-7687.2007.00572.x

Lattenkamp, E. Z., Vernes, S. C., and Wiegrebe, L. (2018). Volitional control of social vocalisations and vocal usage learning in bats. J. Exp. Biol. 221:jeb180729. doi: 10.1242/jeb.180729

Lattenkamp, E. Z., Vernes, S. C., and Wiegrebe, L. (2020). Vocal production learning in the pale spear-nosed bat, Phyllostomus discolor. Biol. Lett. 16:20190928. doi: 10.1098/rsbl.2019.0928

MacNamara, J. (1972). Cognitive basis of language learning in infants. Psychol. Rev. 79, 1-13. doi: 10.1037/h0031901

Manske, U., and Schmidt, U. (1979). Untersuchungen zur optischen Musterunterscheidung bei der Vampirfledermaus, Desmodus rotundus. Z. Tierpsychol. 49, 120-131. doi: 10.1111/j.1439-0310.1979.tb00280.x

Möhres, F. P., and Kulzer, E. (1956). Über die Orientierung der Flughunde (Chiroptera-Pteropodidae). Z. Vergl. Physiol. 38, 1-29. doi: 10.1007/BF003 38621

Neuweiler, G. (1969). Verhaltensbeobachtungen an einer indischen Flughundkolonie (Pteropus g. giganteus Brünn). Z. Tierpsychol. 26, 166-199. doi: $10.1111 / j .1439-0310.1969 . t b 01944 . x$

Neuweiler, G. (1989). Foraging ecology and audition in echolocating bats. Trends Ecol. Evol. 4, 160-166. doi: 10.1016/0169-5347(89)90120-1

Nieder, A. (2009). Prefrontal cortex and the evolution of symbolic reference. Curr. Opin. Neurobiol. 19, 99-108. doi: 10.1016/j.conb.2009.04.008

Nilsson, M., Lindström, K., Amundin, M., and Persson, H. W. (2004). Echolocation and visualization interface system ELVIS. Abstracts from the Symposium on the Occasion of the 50th Anniversary of Echocardiography, Sweden, 24, 169-178.

Oller, D. K. (1980). "The emergence of the sounds of speech in infancy" in Child phonology. eds. G. H. Yeni-Komshian, J. F. Kavanagh and C. A. Ferguson (New York: Academic Press), 93-112.

Page, R. A., and Bernal, X. E. (2020). The challenge of detecting prey: private and social information use in predatory bats. Funct. Ecol. 34, 344-363. doi: 10.1111/1365-2435.13439

Page, R. A., and Ryan, M. J. (2005). Flexibility in assessment of prey cues: frog-eating bats and frog calls. Proc. R. Soc. Lond. B Biol. Sci. 272, 841-847. doi: $10.1098 / \mathrm{rspb} .2004 .2998$

Page, R. A., and Ryan, M. J. (2006). Social transmission of novel foraging behavior in bats: frog calls and their referents. Curr. Biol. 16, 1201-1205. doi: $10.1016 /$ j.cub.2006.04.038

Page, R. A., von Merten, S., and Siemers, B. M. (2012). Associative memory or algorithmic search: a comparative study on learning strategies of bats and shrews. Anim. Cogn. 15, 495-504. doi: 10.1007/s10071-012-0474-1

Patriquin, K. J., Kohles, J. E., Page, R. A., and Ratcliffe, J. M. (2018). Bats without borders: predators learn novel prey cues from other predatory species. Sci. Adv. 4:eaaq0579. doi: 10.1126/sciadv.aaq0579

Pepperberg, I. M. (1987). Acquisition of the same/different concept by an African Grey parrot (Psittacus erithacus): learning with respect to categories of color, shape, and material. Anim. Learn. Behav. 15, 423-432. doi: 10.3758/ BF03205051 
Pepperberg, I. M. (1992). A review of the effects of social interaction on vocal learning in African grey parrots (Psittacus erithacus). Netherlands J. Zool. 43, 104-124. doi: 10.1163/156854293X00241

Pepperberg, I. M. (1994). Vocal learning in grey parrots (Psittacus erithacus): effects of social interaction, reference, and context. Auk 111, 300-313. doi: $10.2307 / 4088595$

Pepperberg, I. M. (2002). Cognitive and communicative abilities of grey parrots. Curr. Dir. Psychol. Sci. 11, 83-87. doi: 10.1111/1467-8721.00174

Pepperberg, I. M. (2006). Grey parrot numerical competence: a review. Anim. Cogn. 9, 377-391. doi: 10.1007/s10071-006-0034-7

Pepperberg, I. M. (2009). The Alex studies: Cognitive and communicative abilities of grey parrots. Cambridge, Massachusetts: Harvard University Press.

Petitto, L. A., and Marentette, P. F. (1991). Babbling in the manual mode: evidence for the ontogeny of language. Science 251, 1493-1496. doi: 10.1126/ science. 2006424

Prat, Y., Azoulay, L., Dor, R., and Yovel, Y. (2017). Crowd vocal learning induces vocal dialects in bats: playback of conspecifics shapes fundamental frequency usage by pups. PLOS Biol. 15:e2002556. doi: 10.1371/journal. pbio. 2002556

Prat, Y., Taub, M., and Yovel, Y. (2015). Vocal learning in a social mammal: demonstrated by isolation and playback experiments in bats. Sci. Adv. 1:e1500019. doi: 10.1126/sciadv.1500019

Raghuram, H., Thangadurai, C., Gopukumar, N., Nathar, K., and Sripathi, K. (2009). The role of olfaction and vision in the foraging behaviour of an echolocating megachiropteran fruit bat, Rousettus leschenaulti (Pteropodidae). Mamm. Biol. 74, 9-14. doi: 10.1016/j.mambio.2008.02.008

Ratcliffe, J. M., Fenton, M. B., and Galef, B. G. Jr. (2003). An exception to the rule: common vampire bats do not learn taste aversions. Anim. Behav. 65, 385-389. doi: 10.1006/anbe.2003.2059

Reiss, D., and McCowan, B. (1993). Spontaneous vocal mimicry and production by bottlenose dolphins (Tursiops truncatus): evidence for vocal learning. J. Comp. Psychol. 107, 301-312. doi: 10.1037/0735-7036.107.3.301

Ripperger, S., Günther, L., Wieser, H., Duda, N., Hierold, M., Cassens, B., et al. (2019). Proximity sensors on common noctule bats reveal evidence that mothers guide juveniles to roosts but not food. Biol. Lett. 15:20180884. doi: $10.1098 /$ rsbl.2018.0884

Rose, A., Wöhl, S., Bechler, J., Tschapka, M., and Knörnschild, M. (2019). Maternal mouth-to-mouth feeding behaviour in flower-visiting bats, but no experimental evidence for transmitted dietary preferences. Behav. Process. 165, 29-35. doi: 10.1016/j.beproc.2019.06.001

Ross, G., and Holderied, M. W. (2013). "Learning and memory in bats: a case study on object discrimination in flower-visiting bats" in Bat evolution, ecology, and conservation. eds. R. A. Adams and S. C. Pedersen (New York, NY: Springer), 207-224.

Ruczyński, I., and Siemers, B. M. (2011). Hibernation does not affect memory retention in bats. Biol. Lett. 7, 153-155. doi: 10.1098/rsbl.2010.0585

Safi, K., and Kerth, G. (2003). Secretions of the interaural gland contain information about individuality and colony membership in the Bechstein's bat. Anim. Behav. 65, 363-369. doi: 10.1006/anbe.2003.2067

Savage-Rumbaugh, E. S. (1993). "Language learnability in man, ape, and dolphin" in Language and communication. eds. H. L. Roitblat, L. M. Herman and P. E. Nachtigall (New York: Lawrence Erlbaum Associates, Inc), 456-469.

Savage-Rumbaugh, E. S., and Fields, W. M. (2000). Linguistic, cultural and cognitive capacities of bonobos (Pan paniscus). Cult. Psychol. 6, 131-153. doi: 10.1177/1354067X0062003

Savage-Rumbaugh, E. S., and Rumbaugh, D. M. (1978). Symbolization, language, and chimpanzees: a theoretical reevaluation based on initial language acquisition processes in four young Pan troglodytes. Brain Lang. 6, 265-300. doi: 10.1016/0093-934X(78)90063-9

Savage-Rumbaugh, E. S., Rumbaugh, D. M., and Boysen, S. (1980). "Linguistically mediated tool use and exchange by chimpanzees (Pan troglodytes)" in Speaking of apes. eds. T. A. Sebeok and J. Umiker-Sebeok (Boston, MA: Springer), 353-383.

Schusterman, R. J., and Krieger, K. (1984). California sea lions are capable of semantic comprehension. Psychol. Rec. 34, 3-23. doi: 10.1007/BF03394849

Schusterman, R. J., and Krieger, K. (1986). Artificial language comprehension and size transposition by a California sea lion (Zalophus californianus). J. Comp. Psychol. 100, 348-355. doi: 10.1037/0735-7036.100.4.348
Sevcik, R. A., and Savage-Rumbaugh, E. S. (1994). Language comprehension and use by great apes. Lang. Commun. 14, 37-58. doi: 10.1016/0271-5309 (94)90019-1

Shettleworth, S. J. (1998). Cognition, evolution, and behavior. New York: Oxford University Press.

Siemers, B. M. (2001). Finding prey by associative learning in gleaning bats: experiments with a Natterer's bat Myotis nattereri. Acta Chiropterol. 3, 211-215.

Siemers, B. M., and Page, R. A. (2009). "Behavioral studies of bats in captivity: methodology, training and experimental design" in Ecological and behavioral methods for the study of bats. eds. T. H. Kunz and S. Parsons (Baltimore: Johns Hopkins University Press), 373-392.

Simon, R., Holderied, M. W., and Von Helversen, O. (2006). Size discrimination of hollow hemispheres by echolocation in a nectar feeding bat. J. Exp. Biol. 209, 3599-3609. doi: 10.1242/jeb.02398

Simon, R., Knörnschild, M., Tschapka, M., Schneider, A., Passauer, N., and von Helversen, O. (2014). Biosonar resolving power: echo-acoustic perception of surface structures in the submillimeter range. Front. Physiol. 5:64. doi: 10.3389/fphys.2014.00064

Sinha, C. (2004). "The evolution of language: from signals to symbols to systems" in Evolution of communication systems, a comparative approach. eds. D. K. Oller and U. Griebel (Cambridge: MIT Press), 217-235.

Starkhammar, J., Amundin, M., Olsén, H., Almqvist, M., Lindström, K., and Persson, H. W. (2007). "Acoustic touch screen for dolphins, first application of ELVIS - an echo-location visualization and interface system" in Proceedings from the 4th International Conference on Bio-Acoustics, 29; April 10-12, 2007; UK, 63-68.

Stich, K. P., and Winter, Y. (2006). Lack of generalization of object discrimination between spatial contexts by a bat. J. Exp. Biol. 209, 4802-4808. doi: 10.1242/ jeb.02574

Terrace, H. S. (1963). Discrimination learning with and without "errors." J. Exp. Anal. Behav. 6, 1-27. doi: 10.1901/jeab.1963.6-1

Thiele, J., and Winter, Y. (2005). Hierarchical strategy for relocating food targets in flower bats: spatial memory versus cue-directed search. Anim. Behav. 69, 315-327. doi: 10.1016/j.anbehav.2004.05.012

Tomasello, M. (1992). The social bases of language acquisition. Soc. Dev. 1, 67-87. doi: 10.1111/j.1467-9507.1992.tb00135.x

Tomasello, M. (2000). Culture and cognitive development. Curr. Dir. Psychol. Sci. 9, 37-40. doi: 10.1111/1467-8721.00056

Tomasello, M. (2003). "The key is social cognition" in Language in mind: Advances in the study of language and thought. eds. D. Gentner and S. Goldin-Meadow (Cambridge: MIT Press), 47-57.

Tomasello, M., Call, J., and Hare, B. (1998). Five primate species follow the visual gaze of conspecifics. Anim. Behav. 55, 1063-1069. doi: 10.1006/ anbe. 1997.0636

Tuttle, M. (2019). How I photograph bats. Merlin Tuttle's Bat Conservation, Resources. Available at: https://www.merlintuttle.org/resources/how-iphotograph-bats/ (Accessed October 31, 2020).

Vihman, M. M. (2014). Phonological development: The first two years. USA: John Wiley and Sons.

Vihman, M. M., Ferguson, C. A., and Elbert, M. (1986). Phonological development from babbling to speech: common tendencies and individual-differences. Appl. Psycholinguist. 7, 3-40. doi: 10.1017/S0142716400007165

Voigt, C. C., Behr, O., Caspers, B., von Helversen, O., Knörnschild, M., Mayer, F., et al. (2008). Songs, scents, and senses: sexual selection in the greater sacwinged bat, Saccopteryx bilineata. J. Mammal. 89, 1401-1410. doi: 10.1644/08-MAMM-S-060.1

Voigt, C. C., and Streich, W. J. (2003). Queuing for harem access in colonies of the greater sac-winged bat. Anim. Behav. 65, 149-156. doi: 10.1006/ anbe.2002.2031

von Helversen, D. (2004). Object classification by echolocation in nectar feeding bats: size-independent generalization of shape. J. Comp. Physiol. A 190, 515-521. doi: 10.1007/s00359-004-0492-9

Walter, M. H., and Schnitzler, H. U. (2019). Spectral call features provide information about the aggression level of greater mouse-eared bats (Myotis myotis) during agonistic interactions. Bioacoustics 28, 1-25. doi: 10.1080/0952 4622.2017.1359798

Wilkinson, G. S., and Boughman, J. (1998). Social calls coordinate foraging in greater spear-nosed bats. Anim. Behav. 55, 337-350. doi: 10.1006/anbe.1997.0557 
Wilkinson, G. S., and Boughman, J. W. (1999). "Social influences on foraging in bats" in Mammalian social learning: comparative and ecological perspectives. eds. H. O. Box and K. R. Gibson (Cambridge: Cambridge University Press), 189-204.

Wilkinson, G. S., Carter, G., Bohn, K. M., Caspers, B., Chaverri, G., Farine, D., et al. (2019). Kinship, association, and social complexity in bats. Behav. Ecol. Sociobiol. 73:7. doi: 10.1007/s00265-018-2608-1

Winter, Y., von Merten, S., and Kleindienst, H. U. (2005). Visual landmark orientation by flying bats at a large-scale touch and walk screen for bats, birds and rodents. J. Neurosci. Methods 141, 283-290. doi: 10.1016/j.jneumeth.2004. 07.002

Wright, G. S. (2016). "Social learning and information transfer in bats: conspecific influence regarding roosts, calls, and food" in Sociality in bats. ed. J. Ortega (Switzerland: Springer Press), 211-230.

Wright, G. S., Wilkinson, G. S., and Moss, C. F. (2011). Social learning of a novel foraging task by big brown bats, Eptesicus fuscus. Anim. Behav. 82, 1075-1083. doi: 10.1016/j.anbehav.2011.07.044
Yu, C., Luo, J., Wohlgemuth, M., and Moss, C. F. (2019). Echolocating bats inspect and discriminate landmark features to guide navigation. J. Exp. Biol. 222:jeb191965. doi: 10.1242/jeb.191965

Zhao, H., Rossiter, S. J., Teeling, E. C., Li, C., Cotton, J. A., and Zhang, S. (2009). The evolution of color vision in nocturnal mammals. Proc. Natl. Acad. Sci. U. S. A. 106, 8980-8985. doi: 10.1073/pnas.0813201106

Conflict of Interest: The authors declare that the research was conducted in the absence of any commercial or financial relationships that could be construed as a potential conflict of interest.

Copyright (c) 2020 Knörnschild and Fernandez. This is an open-access article distributed under the terms of the Creative Commons Attribution License (CC BY). The use, distribution or reproduction in other forums is permitted, provided the original author(s) and the copyright owner(s) are credited and that the original publication in this journal is cited, in accordance with accepted academic practice. No use, distribution or reproduction is permitted which does not comply with these terms. 